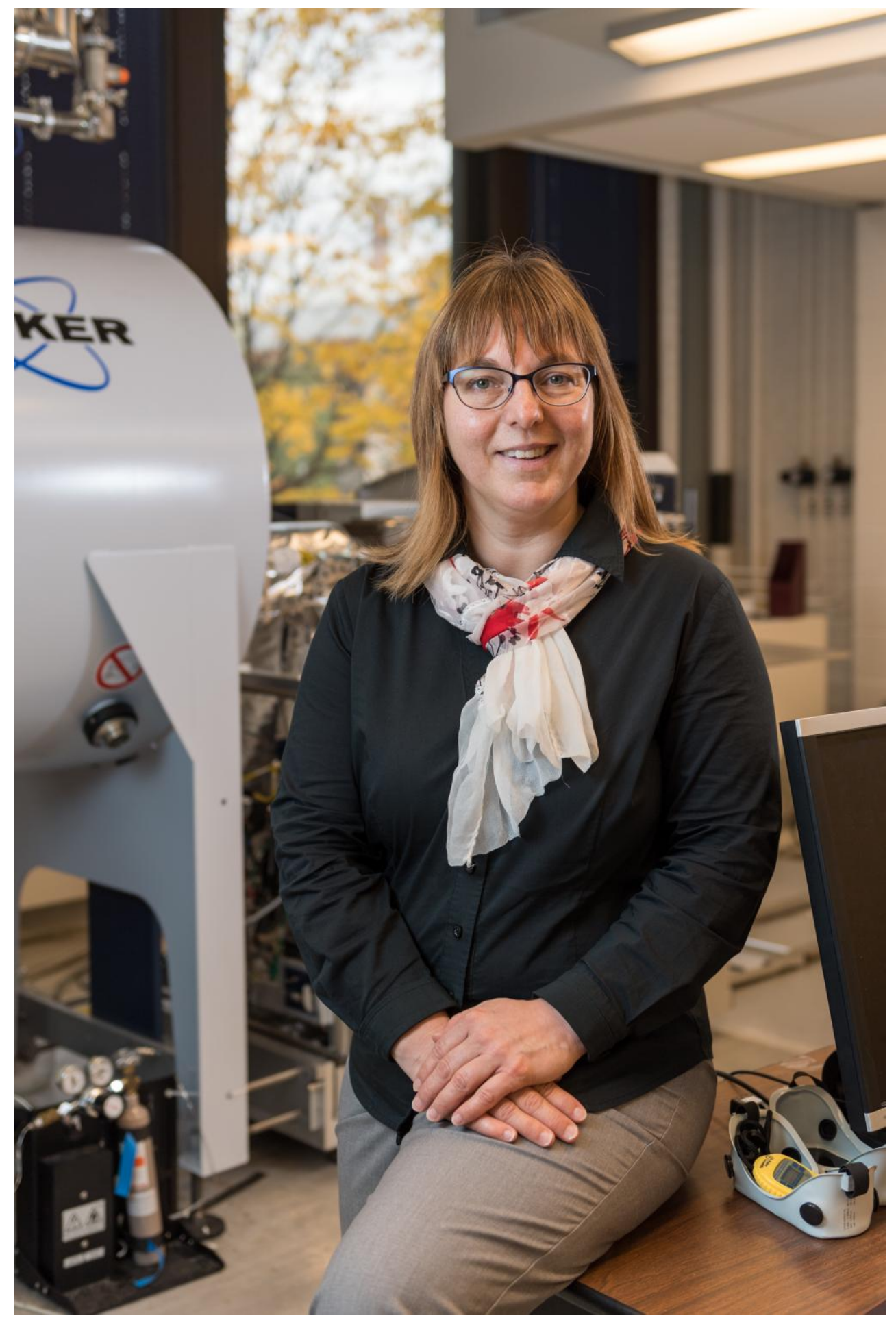




\section{Focus Honoring Dr. Kristina "Kicki" Håkansson, Recipient of the 2016 ASMS Biemann Medal}

It is a pleasure to introduce a special focus of the Journal of the American Society for Mass Spectrometry to celebrate the accomplishments of the 2016 Biemann Medalist, Dr. Kristina (Kicki) Håkansson. This issue contains 8 articles around the theme of "Using electrons and radical chemistry to characterize biological molecules". I thank all the authors and reviewers for helping this issue come to fruition. In order for readers to learn more about Kicki's background and motivations, an "interview" format has been adopted.

\section{Interview with Kristina Håkansson:}

Q: Many of us were inspired to pursue science by our high school teachers. What were your chemistry teachers like at school?

Kicki's Answer: My high school math, physics and chemistry teachers were all wonderful. I was in a 'natural sciences' program with a high achieving group of students. I do recall that the Chemistry teacher had to give most of us the highest possible grade ( 5 on a scale from 1 to 5 ) after we took the national standardized test. One memory is that he taught us the optimal way of doing dishes. I also fondly remember the hands-on demonstrations.

\section{Q: What made you choose science for your tertiary education?}

Kicki's Answer: I was mainly applying to medical schools but then I received a flyer in the mail saying something like 'are you the kind of student who likes BOTH Chemistry/Biology AND Math/Physics, then this new program is for you'. This wording resonated with me and I applied to the new program in Molecular Biotechnology at the School of Engineering at Uppsala University. I was admitted to this program but not to medical school and decided to give it a try. It turns out I really liked the breadth of the courses I was taking and the overall environment in the engineering school so I stayed in the 4.5 year program to earn my M.Sc. degree after doing research involving atomic force microscopy (AFM) of DNA.

\section{Q: What was your first research experiment in chemistry?}

Kicki's Answer: The last semester of the M.Sc. program required full time research and a thesis. I did not know exactly what I wanted to do but attended a seminar by Prof. Bo Sundqvist (Professor of Ion Physics and co-founder of the Molecular Biotechnology M.Sc. program) in which he showed one of the first AFM images of an antibody. I was blown away by the fact that you could see the $\mathrm{Y}$-shape of a single molecule with this technique! Following this seminar, I contacted Prof. Sundqvist and he agreed to accept me into his laboratory (which also did a lot of mass spectrometry but that came later). My first experiments involved figuring out the optimum buffer conditions for imaging DNA with AFM, i.e., how to avoid spaghetti-like super-coiled structures that couldn't be analyzed very well and instead get plasmids to lay down on mica as nice circular structures. 
Q: You moved from Sweden to the USA to pursue your post-doctoral studies and then stayed on to establish your independent research career. Tell us something about what motivated you to make such a move and why you decided to stay in the USA.

Kicki's Answer: I transitioned to mass spectrometry-based research for my Ph.D. thesis (in the same group as my M.Sc. research but under supervision of Prof. Per Hakansson (no relation)). We were fortunate to receive an FT-ICR instrument about half-way through my Ph.D. and I was amazed by the high performance compared with the time-of-flight instruments I had worked on until then. I wanted to learn more about FT-ICR MS and was thrilled to receive an opportunity to work with one of its co-inventors, Prof. Alan Marshall, for my postdoc. Alan was a wonderful mentor and pushed me onto the path of an independent career. I had not considered applying for academic positions in the US as I did not do any schooling here but he convinced me to try and was highly supportive and helpful throughout the entire process up until the moment when I had to decide between three offers. At that time, he told me he was not going to influence me one way or another. I chose to go to Michigan and I think it only hurt him a little being a big fan of Ohio State football (I barely knew about football rivalries at the time).

\section{Q: What is your favorite piece of work that you have been involved in?}

Kicki's Answer: This is difficult to answer so I will list two: one is a four-way collaboration with medicinal chemists, X-ray crystallographers and Cryo-EM scientists to reveal how the structure of a $2 \times 160 \mathrm{kDa}$ polyketide synthase undergoes dramatic changes during its catalytic cycle depending on which small molecule(s) are covalently loaded onto it. I loved being part of this interdisciplinary team and gaining insights into a molecular machine that previously had been viewed as a "black box". High resolution LC/MS data were essential to figure out the covalent state of each proteoform we looked at. A favorite in my own lab was the discovery of negative ion ECD - we were so excited when we saw the first charge increased species!

Q: Reading your papers, one get's the impression that you like doing technically challenging experiments. Is that correct?

Kicki's Answer: Absolutely - it is so rewarding when you can get all the components to work at the same time! niECD is one example - it took a long time but was really worth it!

\section{Q: Which scientist from history would you like to meet?}

Kicki's Answer: This is not something I have ever really thought much about - the answer off the top of my head would be Marie Curie. I was so excited she was one of the first scientists discussed in my daughter's first middle school science class this year. To quote Wikipedia "She was the first woman to win a Nobel Prize, the first person and only woman to win twice, the only person to win a Nobel Prize in two different sciences, and was part of the Curie family legacy of five Nobel Prizes. She was also the first woman to become a professor at the University of Paris, and in 1995 
became the first woman to be entombed on her own merits in the Panthéon in Paris." Hard to get more inspiring than that!

\section{Q: How do you balance family life and your productive scientific career?}

Kicki's Answer: I get asked this question quite a lot. The short answer is that I'm still figuring out how to do this well. However, I recently was asked to give a lunch seminar on this topic and gave it some more thought. I found Randi Zuckerberg's suggestions very insightful that you can only have three out of the following five things at any given time: career, family, sleep, friends and exercise. You need to rotate these in and out every day and she was most likely to give up the latter two. However, friends have always been really important to me and I am more prone to sacrifice sleep (although it has to be caught up on eventually). As a single parent, I would not have made it where I am today without a network of very close friends who have helped me a lot with my children and their activities. One of my daughters is a competitive figure skater, which has posed some unique challenges - it definitely takes a village!

\section{Q: If you have to provide advice to an early career researcher about establishing a career in science, what will they be?}

Kicki's Answer: Seek out a network of mentors! I was fortunate to be in a Department that has a formal process with a designated mentor (for me Professor Robert T. Kennedy, one of the top analytical chemists in the nation - I was very lucky!). However, peer mentoring was equally important. We had "assistant professor lunch" every month and it was a wonderful forum for trouble shooting anything from how to get an order placed to how to manage challenges with students. The ASMS community has also been highly valuable in this regard.

\section{Q: What are the ultimate goals for Chemists?}

Kicki's Answer: As a Chemistry Department, we recently had a conversation related to this topic with the incoming Dean of the College of Literature, Science and the Arts, who is a political scientist. His predecessor is a historian, further emphasizing the broadness of the College we belong to. One answer is that Chemistry is uniquely positioned as the "central" science with interfaces to, e.g., biology, physics, medicine, and earth science. Chemistry contributes a molecular level understanding of everything that occurs on this planet and beyond. Our goal should thus be to serve as a nucleus for interdisciplinary collaborations resulting in transformative science.

\section{Richard A.J. O'Hair}

Associate Editor, JASMS

The University of Melbourne

Victoria 3010, Australia

e-mail: rohair@unimelb.edu.au 


\section{University Library}

\section{- M M N E R VA A gateway to Melbourne's research publications}

Minerva Access is the Institutional Repository of The University of Melbourne

Author/s:

O'Hair, RAJ

Title:

Focus Honoring Dr. Kristina "Kicki" Hakansson, Recipient of the 2016 Biemann Medal

Date:

2017-09-01

Citation:

O'Hair, R. A. J. (2017). Focus Honoring Dr. Kristina "Kicki" Hakansson, Recipient of the 2016 Biemann Medal. JOURNAL OF THE AMERICAN SOCIETY FOR MASS SPECTROMETRY, 28 (9), pp.1739-1740. https://doi.org/10.1007/s13361-017-1729-5.

Persistent Link:

http://hdl.handle.net/11343/283039 